\title{
7
}

\section{Actualities and Perspectives in Continuous Epidural Analgesia During Childbirth in Romania}

\author{
Virgil Dorca ${ }^{1}$, Dan Mihu², Diana Feier ${ }^{3}$, Adela Golea ${ }^{4}$ and Simona Manole ${ }^{3}$ \\ ${ }^{1}$ ATI III Clinic of Obstetrics and Gynecology "Dominic Stanca", Faculty of Medicine. \\ ${ }^{2}$ Clinic of Obstetrics and Gynecology "Dominic Stanca", Faculty of Medicine, \\ ${ }^{3 R a d i o l o g y}$ and Medical Imaging Clinic, Faculty of Medicine, \\ ${ }^{4}$ University Emergency County Hospital, \\ University of Medicine and Pharmacy, Cluj-Napoca, \\ Romania
}

"To the woman he said, I will make your pains in childbearing very severe; with painful labour you will give birth to children"

(Genesis 3, 16)

\section{Introduction}

Starting from this biblical precept, Christian religions used to regard pain occurring at childbirth as divine punishment. Given the fact that childbirth pain is perceived as very severe and evaluated as more intense than toothache, phantom limb pain or even the ache caused by a fracture, with the progress of society, human condition and the status of women, childbirth pain has become ever more difficult to accept.

The epidural therapeutic administration of drugs was practically initiated in 1884, when Corning, a New York neurologist, administered cocaine through a needle inserted at level T11-T12 [Bonica J, Mc Donald JS, 1995]. It was not until 1901 that Cathelin [Cathelin MF, 1901] reported in France a caudal epidural anesthesia. In 1921, Pages used lumbar epidural anesthesia, and in 1931, Dogliotti described the method of locating the epidural space through "the technique of loss of resistance" (LOR) [Dogliotti AM, 1934; Abboud T et al., 1980]. The first use of lumbar epidural analgesia in obstetrics remains somewhat uncertain. In 1935, Graffagnino and Seyler [Bonica J, Mc Donald JS, 1995; Graffagnino P, Seyler LW, 1938] published in American literature the first reports on the use of epidural analgesia in obstetrics. In January 1947, Manuel Curbelo in Cuba used an ureteral catheter [Dogliotti AM, 1934; Graffagnino P, Seyler LW, 1938] inserted through a Tuohy needle and thus achieved the continuous epidural. Immediately after, Umstead and Dufresne applied this technique in obstetrics. In 1949, Cleland described the double catheter technique. In the 1950s, Bonica and Bromage described the superiority of lumbar epidural analgesia compared to caudal analgesia. 


\section{The situation of epidural analgesia in childbirth in Romania}

Although epidural analgesia is becoming increasingly popular throughout the world, its applicability in Romania is still limited. In our studies, we have attempted to analyse the reasons for which women request or refuse epidural analgesia at childbirth, the level of knowledge of the participants in the study with regard to this method and the situation of epidural analgesia at childbirth in the main county hospitals, university clinics and private hospitals across Romania.

Starting from the premise that "maternal wish is a sufficient justification for alleviating pain during labour", as mentioned by the American College of Obstetrics and Gynaecology and the American Society of Anaesthesiologists [American Society of Anesthesiologists Task Force on Obstetric Anesthesia, 2007], it is important to understand the pain that occurs during labour. Epidural analgesia is a means of alleviating pain which is preferred by women in developed countries [Robert R, Gaiser RR, 2005]. In a study conducted by Minhas et al. (2005) [Minhas MR et al., 2005], 76\% of the women knew that epidural analgesia was a method of alleviating pain; nevertheless, only $19 \%$ made use of this technique. From this point of view, we have attempted to conduct a "market study" regarding the situation of epidural analgesia in childbirth in Romania.

In our study, we have interviewed 205 parturients, evaluated by means of a questionnaire containing 12 sections, the collected data being compiled using Med Calc version 9.1.

Since the variables tested have not brought forth a normal distribution, the Kruskal-Wallis, Mann-Whitney tests and Spearman's correlation coefficient have been chosen as test patterns. With descriptive statistics (average, standard deviation, frequency tables), the $t$ test has been utilised in comparing nominal data, while the chi-square test has been made use of for qualitative data. A confidence interval of $95 \%$ and $p<0.05$ have been used in the evaluation.

In our study, $25,36 \%$ of the parturients opted for epidural analgesia, namely a percentage of 84,61 of the parturients that were aware of the indications, advantages and potential disadvantages of the procedure (See Table 1).

A percentage of 86,27 of the women that did not give birth with epidural analgesia did not hold any information concerning the procedure. A painless labour had a positive effect on the parturients, due to an increase in maternal satisfaction, while providing them with the possibility to participate actively in the act of childbirth. The reasons why they chose to give birth with epidural analgesia was the fear of pain, or previous positive experiences, both personal and those of acquaintances. (See Table 2)

A high percentage of the parturients feared pain during labour $(57,7 \%)$. In this study, the reasons for which they refused undergoing labour on epidural analgesia were the wish to have a natural childbirth, previous negative experience regarding epidural analgesia, negative experiences of other patients and fear of side effects. (See Table 3)

As shown by Bussche et al. [Bussche EV et al., 2007], the main factor that determined the parturients' decision was social influence. There are studies which report numerous factors that influence the decision to use epidural analgesia, such as age, level of education and 
health insurance status [Atherton MJ et al., 2004; Obst TE et al., 2001; Rust G et al., 2004; Salim R et al., 2005].

\begin{tabular}{|c|c|c|c|c|c|}
\hline \multirow[b]{2}{*}{ Characteristics } & \multicolumn{2}{|c|}{$\begin{array}{l}\text { Childbirth with } \\
\text { epidural analgesia } \\
(n=52)\end{array}$} & \multicolumn{2}{|c|}{$\begin{array}{l}\text { Childbirth without } \\
\text { epidural analgesia } \\
(n=153)\end{array}$} & \multirow[b]{2}{*}{$p$} \\
\hline & $\mathbf{N}$ & $\%$ & $\mathbf{n}$ & $\%$ & \\
\hline \multicolumn{6}{|l|}{ Age, years } \\
\hline$\leq 20$ & 7 & 13,46 & 45 & 29,41 & \multirow{3}{*}{0,80} \\
\hline $21-30$ & 38 & 73,08 & 75 & 49,02 & \\
\hline$\geq 30$ & 7 & 13,46 & 33 & 21,57 & \\
\hline \multicolumn{6}{|l|}{ Level of education promoted } \\
\hline Secondary School & 2 & 3,85 & 53 & 34,64 & \multirow{3}{*}{0,05} \\
\hline High School & 18 & 34,62 & 85 & 55,55 & \\
\hline University & 32 & 61,53 & 15 & 9,81 & \\
\hline \multicolumn{6}{|l|}{$\begin{array}{l}\text { Knowledge regarding epidural } \\
\text { analgesia in childbirth }\end{array}$} \\
\hline $\begin{array}{rr} & \text { Yes } \\
\end{array}$ & 44 & 84,61 & 21 & 13,73 & \multirow[b]{2}{*}{0,02} \\
\hline No & 8 & 15,39 & 132 & 86,27 & \\
\hline
\end{tabular}

Table 1. Characteristics of patients included in the study $(\mathrm{N}=205)$

\begin{tabular}{|l|c|r|}
\hline Reasons & n & \% \\
\hline Fear of pain & 30 & 57,70 \\
\hline Previous negative personal experience & 12 & 23,07 \\
\hline Positive experience of other people & 10 & 19,23 \\
\hline
\end{tabular}

Table 2. Reasons why the parturients chose epidural analgesia $(n=52)$

\begin{tabular}{|l|r|r|}
\hline Reason & n & \% \\
\hline The wish to have a natural childbirth & 7 & 33,40 \\
\hline Personal negative experience & 5 & 23,80 \\
\hline Negative experience of other people & 5 & 23,80 \\
\hline Fear of side effects & 4 & 19,04 \\
\hline Advice of gynaecologist & 6 & 28,57 \\
\hline
\end{tabular}

Table 3. Reasons why the parturients refused epidural analgesia $(n=21)$

A low percentage of epidural analgesia procedures during labour is noticed $(25,36 \%)$, with a majority of $61,53 \%$ among patients that graduated from higher education. Most had been informed about these techniques of alleviating pain (84.61\%). There was a significant difference with respect to the level of education between the group that benefited from epidural analgesia and the one that did not experience the procedure $(p=0,05)$. The women that gave birth without analgesia $(74,64 \%)$ were mostly high school graduates $(5,55 \%)$ and did not have sufficient information on epidural analgesia in childbirth $(87,27 \%)$. 
The argument that upholds this conclusion may be the fact that epidural analgesia is not largely utilised in childbirth in Romania. According to the 2009 statistics, epidural analgesia is used by approximately $78 \%$ of women in natural childbirths within private clinics. Even though the number of private clinics is not considerable in our country, they are more prone to promoting analgesia during labour, with a significant difference $(p<0,0001)$ compared to university hospitals and county units. (SeeFig.1)

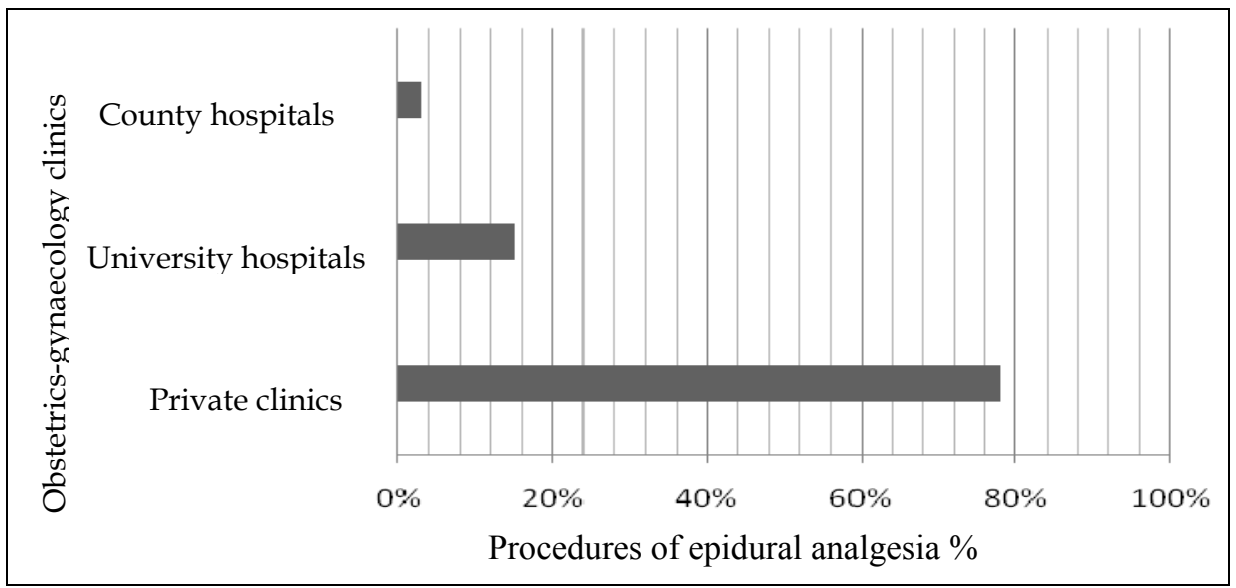

Fig. 1. The percentage of epidural analgesia procedures in the main obstetrics clinics in Romania

The very small percentage (3\%) of the number of epidural analgesia in county hospitals may be explained by the staff's lack of experience and the shortage of appropriate materials [El-Hamamy E, Arulkumaran S, 2005]. Moreover, young doctors do not benefit from the proper environment so as to learn the correct procedure. Their internship in an obstetrics-gynaecology hospital is far too short to provide them with suitable experience. For this reason, there is a phenomenon of parturient migration from city and county hospitals to university and private ones. Parturients prefer hospitals with high-tech equipment and personnel with appropriate experience. A worrying aspect is the fact that the Romanian public does not have sufficient information on this topic and, moreover, public insurance programmes do not cover epidural analgesia at childbirth. Of the total number of women having undergone the procedure, only 4 (7,69\%) experienced pain in the place of anesthesia. After childbirth, the latter stated they were displeased with epidural analgesia and that they would not encourage the use of this means of alleviating pain. The patients that benefited from epidural analgesia in childbirth without the side effects of the procedure exhibited a high level of satisfaction. El-Hamamy \& Arulkumaran have shown that in this case, women did not feel pain during labour, childbirths occurred successfully and women were aware of all events during labour, while feeling comfortable [El-Hamamy E, Arulkumaran S, 2005].

It is our view that pregnant women have to be informed, by means of educational materials, in order to become aware of the directions, benefits, side effects and potential complications of this procedure. It is necessary to have qualified personnel in order to achieve a safe and 
painless childbirth for anyone who opts for pain alleviation during this event, through epidural analgesia [ Dorca V et al., 2011].

\section{PCEA vs CEI}

In Romania, the question that arises regarding the administration of local anaesthetic refers to either "top-up" or CEI, although the unwanted side effects like intense motor block [Ferrante $\mathrm{F} \mathrm{M}$ et al., 1994] are well-known, despite testing various dosages and combinations of anaesthetics [Ferrante F M et al., 1994; Van der Vyver M et al., 2002].

In our studies, we have used a method that is popular with developed countries and not in Romania, introduced in 1988 by D. Gambling (PCEA), in an attempt to reduce the side effects of the other methods, by looking for the drug, dosage and protocol that are ideal in the improvement of the childbirth process, while providing the parturient with psychological and physical comfort and increased maternal satisfaction [Ferrante $\mathrm{F} \mathrm{M} \mathrm{et} \mathrm{al,}$ 1994; Van der Vyver M et al, 2002; Ferrante F M et al, 1991; Dorca V et al, 2009]. We have compared this method to one that is popular in Romania and used in the West since the 1980's, CEI [Gambling D R et al., 1988].

A number of 94 patients entered the study, as they were followed within the "Dominic Stanca" Clinic of Obstetrics and Gynaecology in Cluj-Napoca, so as to conduct an operational, prospective and randomised study.

The parturients were prospectively randomised in order to benefit from a continuous epidural infusion using levobupivacaine or patient-controlled epidural analgesia (PCEA), using the same substance. The patients that were eligible for the study were above the age of 18, ASA I, primipara/secundipara, they had asked epidural analgesia during labour upon admission, having a gestation time of over 37 weeks and exhibiting cranial presentation of the foetus. The minimum cervical dilatation at the moment of initialising epidural analgesia was of 3-4 cm, with uterine contractions at regular intervals of 5-6 minutes. General contraindications of epidural analgesia were the exclusion criteria from the study protocol. Cervical dilatation of over $6 \mathrm{~cm}$ was also among the exclusion criteria.

The protocol was conducted in the delivery room, with the patient sitting. At the L3-L4 level, a $20 \mathrm{G}$ multi-orifice catheter was inserted with a Tuohy $18 \mathrm{G}$ B-Braun needle, using the LORS technique [Gadalla $\mathrm{F}$ et al., 2003]. The catheter was secured and its position verified with a $3 \mathrm{ml}$ test dose of levobupivacaine $0,250 \mathrm{mg} \%$. The patients that were selected for PCEA had the device installed and were instructed as to its functionality. The explanations focused on the manner in which they have to press the button that triggers the bolus dose and on the timing, which should coincide with the apparition of pain. It was expected that improvement should occur within a few minutes. Levobupivacaine 0,250 mg $10 \mathrm{ml}$ bolus

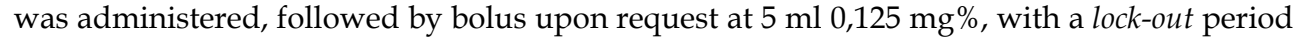
of 15 minutes and a total hourly dose of $20 \mathrm{ml}$. The patients that were administered a continuous epidural infusion were given the same bolus dose of $10 \mathrm{ml}$ levobupivacaine $0,250 \mathrm{mg} \%$, followed by a continuous infusion of levobupivacaine $0,125 \mathrm{mg} \%, 7 \mathrm{ml}$ /hour, the total dose varying according to the duration of childbirth.

During labour, the foetus' heartbeats and uterine activity were monitored with the help of a cardiotocograph, along with the mother's blood pressure, respiratory frequency and 
haemoglobin oxygen saturation. The quantification of pain, using the visual analogical scale (VAS) [Paech M, 2000], which varies from 0 (painless) to 10 (most acute pain), was conducted prior to adding the catheter and, subsequently, every 15 minutes, until the time of expulsion.

The caudal development of the sensitive block grew with the gradual loss of cold sensation [Bromage P R et al., 1964]. The degree of the motor block was appreciated using the Bromage score $(0=$ no motor block: complete flexion of the knee and calf; $1=$ impossibility to lift the leg in extension, knee movements; 2 = impossibility to flex the knee, calf movements; 3 = no calf or knee movements [Bromage P R et al., 1964]). For each patient, we followed the total dose of levobupivacaine utilised, the ratio demand/offer, the time necessary for dilatation, VAS evolution compared to dilatation, the level of maternal satisfaction, the foetus' state at birth (assessed by the neonatologist through the Apgar score, 1 and 5 minutes after birth), the manner of deliverance - vaginally, by caesarean or vacuum extraction. The need for supplementary involvement of medical personnel during labour was equally assessed. Maternal satisfaction was estimated subjectively by the mother according to the level of pain alleviation, the apparition of side effects such as nausea, vomiting, itching, backaches, dural post-puncture headache, both during analgesia and 24 hours after childbirth.

We have chosen for this study isomer $L$ of bupivacaine in a concentration of $0,125-0,250 \%$, due to its low toxicity compared to racemic mixture and we have not used opioids or other adjuvants. Even though these concentrations are considered to be "high" [Owen MD et al., 1998; Meister GC et al., 2000] in studies that have used more diluted solutions with fentanyl as an adjuvant, no statistically significant differences were noticed with regard to the dose of local anaesthetic utilised, the quality of analgesia or maternal satisfaction, when they were compared to the results obtained when using "increased" concentrations [Meister GC et al., 2000; Lyons Gr et al., 2007].

The demographic, anthropometrical and obstetrical parameters of the patients included in the study show statistically significant differences with regard to motor block and instrumental childbirth (See Tables 4, 5).

\begin{tabular}{|l|c|c|c|}
\hline $\begin{array}{l}\text { Demographic and } \\
\text { anthropometric parameters }\end{array}$ & $\begin{array}{c}\text { CEI lot } \\
(53 ; 56,39 \%)\end{array}$ & $\begin{array}{c}\text { PCEA lot } \\
(41 ; 43,61 \%)\end{array}$ & $\mathrm{p}^{*}$ \\
\hline Age (years) & $27,02 \pm 1,23$ & $26,20 \pm 1,92$ & 0,1 \\
\hline Height $(\mathrm{cm})$ & $162,2 \pm 3,27$ & $165,5 \pm 2,29$ & 0,6 \\
\hline Weight $(\mathrm{kg})$ & $76,8 \pm 8,5$ & $78,5 \pm 9,2$ & 0,4 \\
\hline Unipara patients & $27(50,94 \%)$ & $25(60,97 \%)$ & 0,5 \\
\hline
\end{tabular}

Data is expressed as average $\pm \mathrm{SD}$ or number $(\%)$. SD=standard deviation.

Table 4. Demographic and anthropometric parameters of the patients included in the study

The results we have obtained reflect a significant difference from a statistical point of view with regard to the number of instrumental childbirths. $2(4,86 \%)$ of the parturients from the PCEA lot required the obstetrician's instrumental intervention by vacuum extraction, a 
difference which is significantly lower compared to the CEI lot, $14(26,41 \%), p<0,0001$. This can be due to the intense motor block caused by continuous epidural infusion, which prevents the patient from collaborating during labour. The motor block with a Bromage score of above 2 does not enable the patient to use her abdominal muscles in order to facilitate the descent and positioning of the foetus' head. The patient group that benefitted from CEI presented a Bromage score between 2 and 3, which explains the large number of instrumental childbirths. (See Figure 2)

\begin{tabular}{|l|c|c|c|}
\hline Obstetrical parameters & $\begin{array}{c}\text { CEI lot } \\
\mathbf{( 5 3 ;} \mathbf{5 6 , 3 9 \% )}\end{array}$ & $\begin{array}{c}\text { PCEA lot } \\
\mathbf{( 4 1 ;} \mathbf{4 3 , 6 1 \% )}\end{array}$ & $\mathbf{p}^{*}$ \\
\hline Cervical dilatation (cm) & $3,4 \pm 1,1$ & $3,1 \pm 0,8$ & 0,2 \\
\hline Duration of labour (minutes) & $168,5 \pm 123,1$ & $188,3 \pm 133,16$ & 0,2 \\
\hline Total drug dose (ml) & $39,4(9,3-40,1)$ & $35,3(20-190)$ & 0,08 \\
\hline Ratio demand/offer & 0 & $1 / 1$ & NS \\
\hline Sensitive block (VAS linearity) & T10-L3-L4 & T10-L3-L4 & NS \\
\hline Motor block & $21(39,7 \%)$ & $2(4,87 \%)$ & $\mathbf{0 , 0 0 1}$ \\
\hline Maternal satisfaction degree & High & High & \\
\hline State of foetus (APGAR 5') & $8,3(8,12-10,20)$ & $8,4(8,23-11,02)$ & NS \\
\hline Instrumental childbirth (vacuum extraction) & $14(5,66 \%)$ & $2(4,86 \%)$ & $<\mathbf{0 , 0 0 0 1}$ \\
\hline Childbirth by caesarean & $8(15,09 \%)$ & $4(9,75 \%)$ & 0,09 \\
\hline
\end{tabular}

Data is expressed as average $\pm \mathrm{SD}$, average $(\mathrm{CI})$ or number $(\%) . \mathrm{CI}=$ confidence interval

Table 5. Obstetrical parameters of the patients included in the study

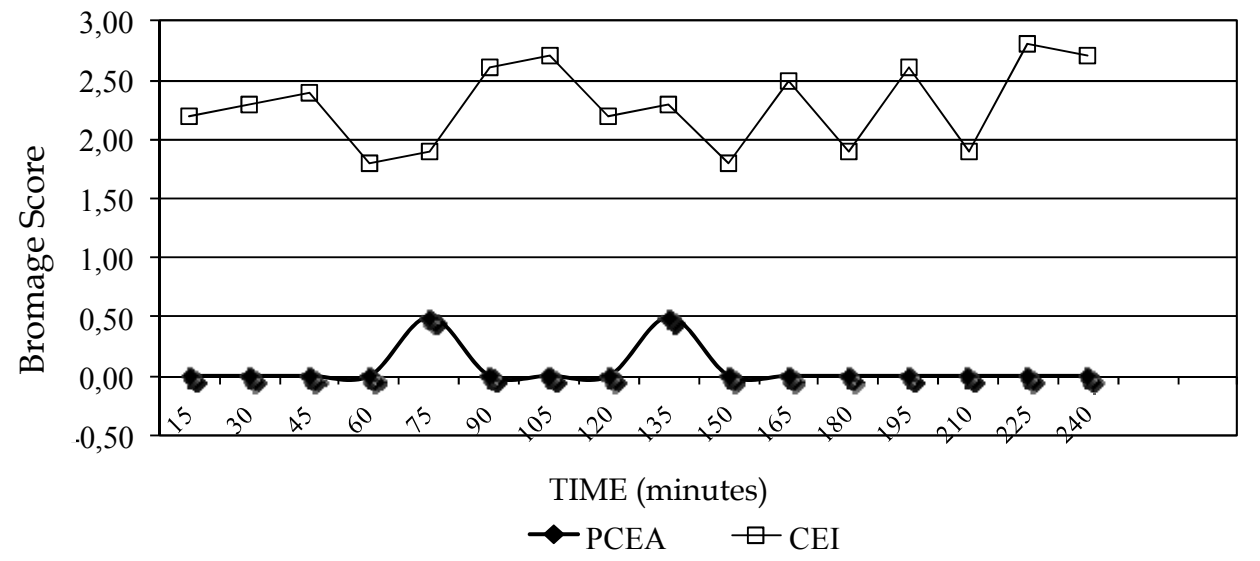

Fig. 2. Bromage score combined with the comparative time between the two lots $(p<0,0001)$

The patients from the PCEA lot maintain the linearity of the Bromage score below value 1, the low percentage of childbirths by vacuum extraction $(4,86 \%)$ being one of the major advantages of this technique. 
The motor block more frequently encountered in the CEI lot was significantly amplified on the right side. Speciality literature attempts to explain this by emphasising the exact spot of the dural puncture with the help of ultrasonography [ Schlotterbeck H. et al., 2008], as we did in the case of 15 patients in collaboration with the Imaging Chair of the University of Medicine and Pharmacy in Cluj-Napoca. We thus managed to accurately determine bone markings, the distance between the skin and the epidural space, the position of the needle in the yellow ligament, the size of the epidural space and the presence/position of the catheter in the epidural space. (See Figures 3, 4, 5, 6)

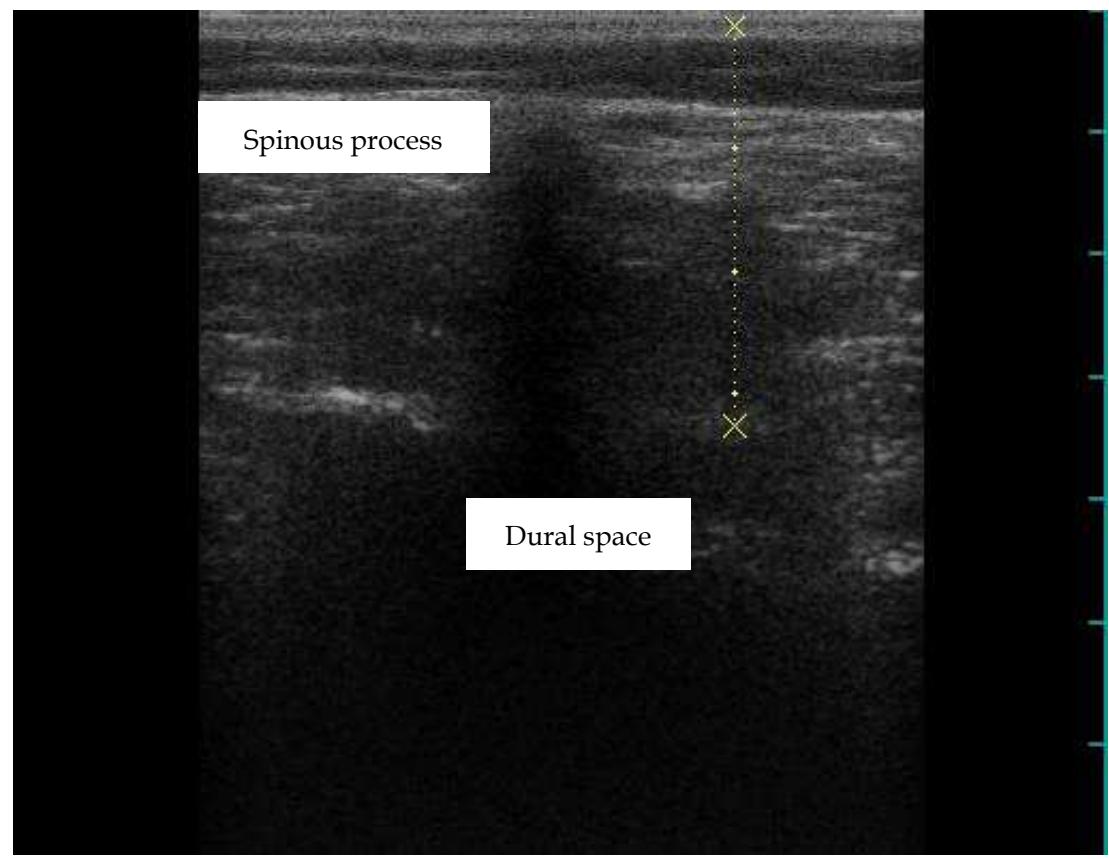

Fig. 3. Transversal section: the spinous process situated in the centre; the dural sac and distance evaluation at the tegument level 


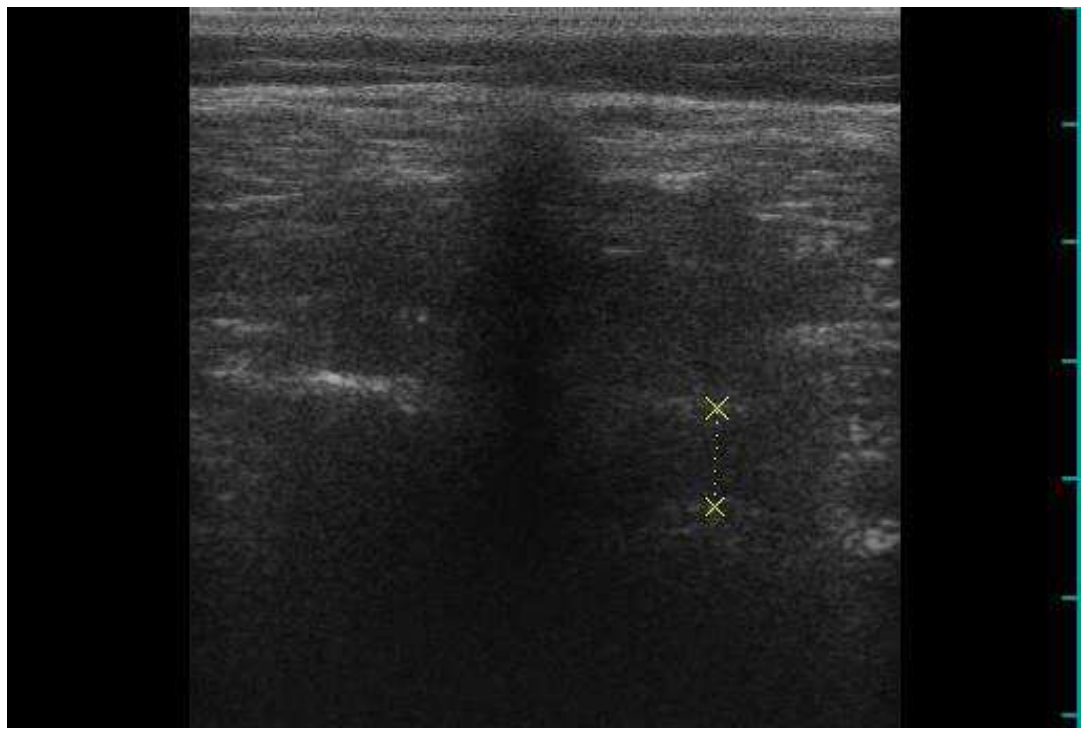

Fig. 4. Transversal section: the spinous process situated in the centre; measurement of the anteroposterior distance of the dural sac; view of the ligament and the posterior dura mater; vertebral body with posterior acoustic shadow

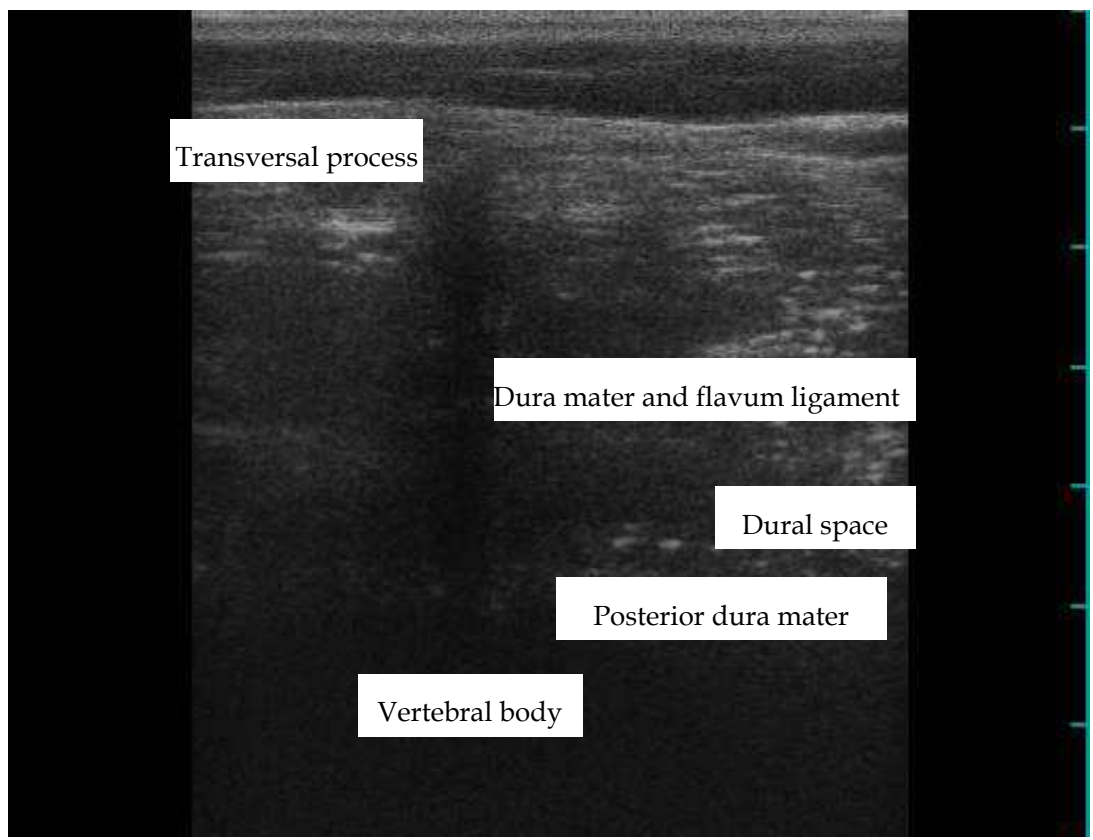

Fig. 5. Parasagittal section with the transverse apophysis (posterior shadow cone) and view of the dural space 


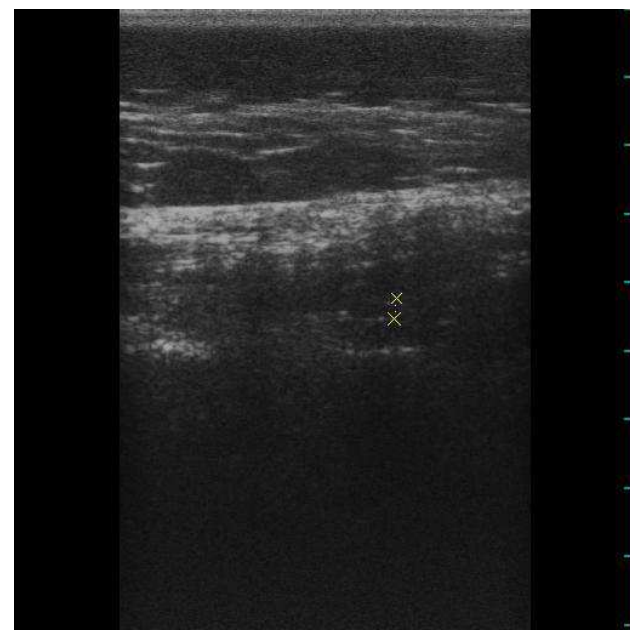

a.

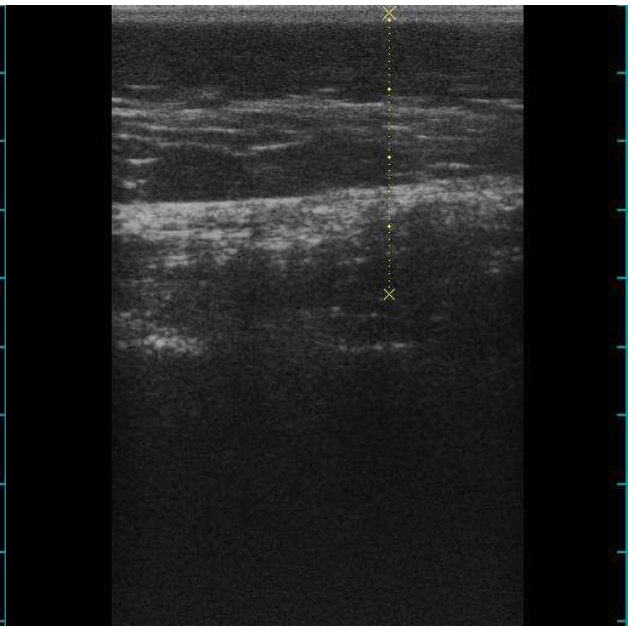

b.

Fig. 6. Parasagittal left section: a - view of catheter situated centrally in the dural sac; $\mathrm{b}$ - measurement of the distance between the tegument and the position of the catheter

Despite the ecographic guidance, we have never managed to place the needle on the median line. (See Figure 7)

One explanation may be the dose and bolus concentration utilised $(0,250 \mathrm{mg} \%$ levobupivacaine), but due to the fact that subsequently, the concentration decreases and remains the same throughout labour, this is not justified. Attempting to explain the motor block, usually occurring asymmetrically (on the right), we photographed the catheters after their retreat from the epidural space. (See Photo 1)

Thus, one can notice the clear connection between the right side position of the catheter and the asymmetric motor block. In patients that did not experience any motor block, it can be noticed the median position of the catheter (See Photo 2), so the connection described between the position of the catheter and the motor block does exist. We have not managed to uncover the reason why in many cases, the catheter is situated laterally (especially on the right).

The PCEA lot receives $20 \mathrm{ml}$ / hour of levobupivacaine $0,125 \mathrm{mg} \%$ and does not develop any motor block, unlike the CEI lot, which is given a lower, but continuous dose, of $7 \mathrm{ml} /$ hour. This favours the apparition of the motor block, probably due to the long period of time during which the substance "lingers" amongst nerve fibres at the level of the top of the catheter, managing in time to reach the middle of the nerve bunch at fibre Aa, which it blocks. (Figure 8). This lingering is favoured in the case of continuous infusion (7 ml/hour) and the fact that during one minute, just two drops are delivered, the anaesthetic substance not being able to diffuse on a long distance. We have also found that, in the case of a continuous infusion, there appears a single drop at the distal end of the three-orifice catheter (See Photo 3), whilst by administering the substance in bolus, it springs from all the three orifices (See Photo 4), its distribution being much more uniform and distant. 

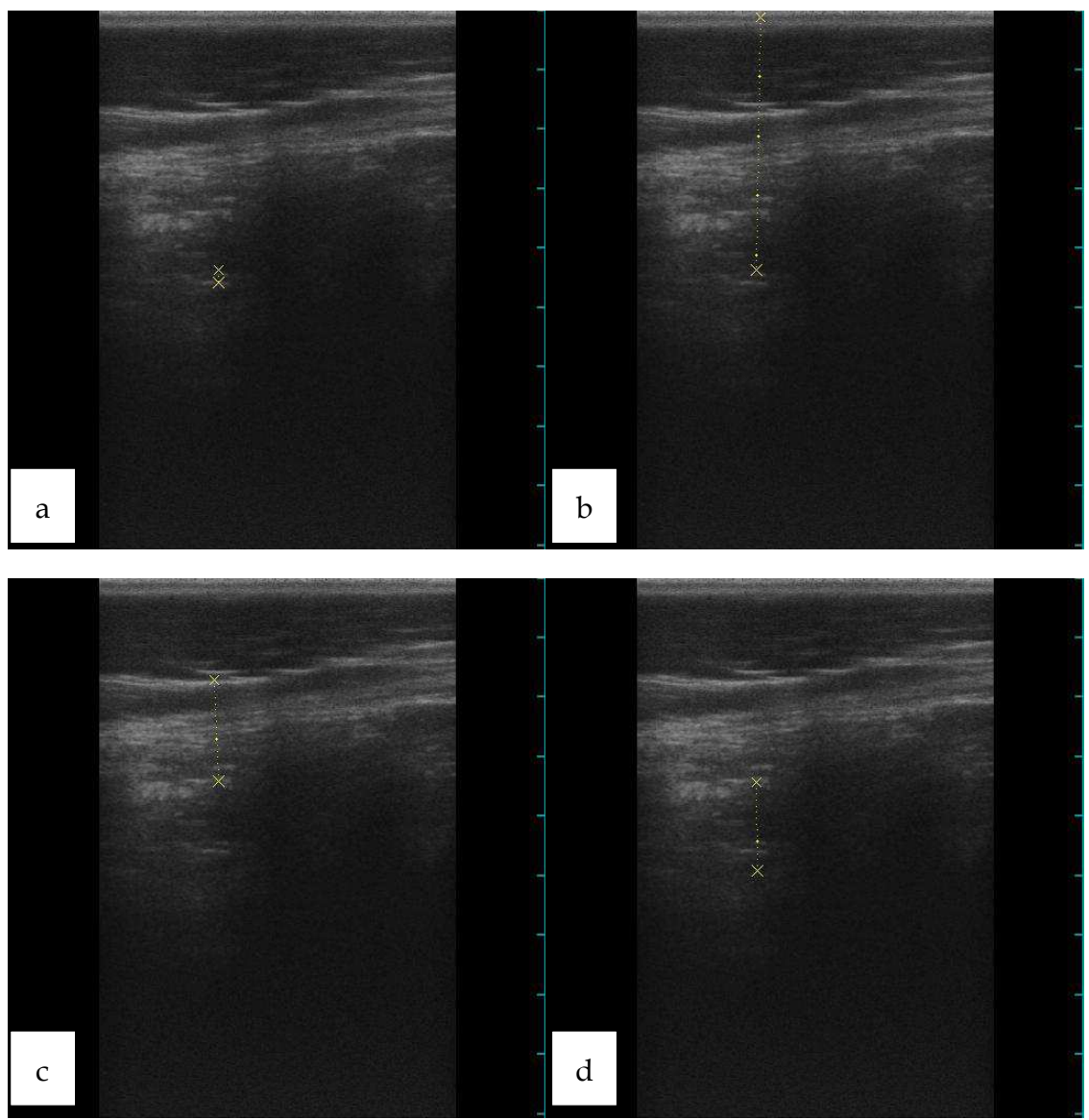

Fig. 7. Parasagittal left section: $a$ - view of the catheter; $b$ - measurement of the distance between the tegument and the position of the catheter; c- thickness of dura mater - flavum ligament; d- latero-lateral dimension of the dural sac, with a view of the right side of the catheter 


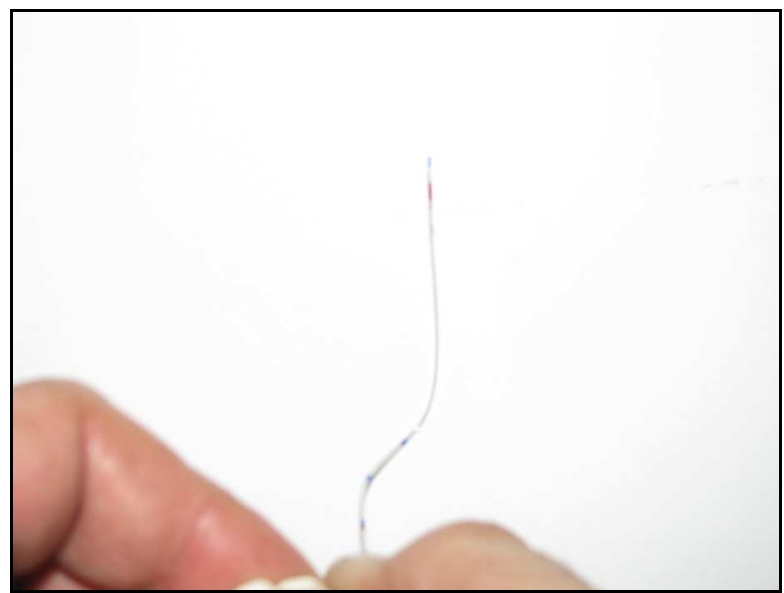

Photo 1. Position of the catheter on the right, after extraction from the epidural space

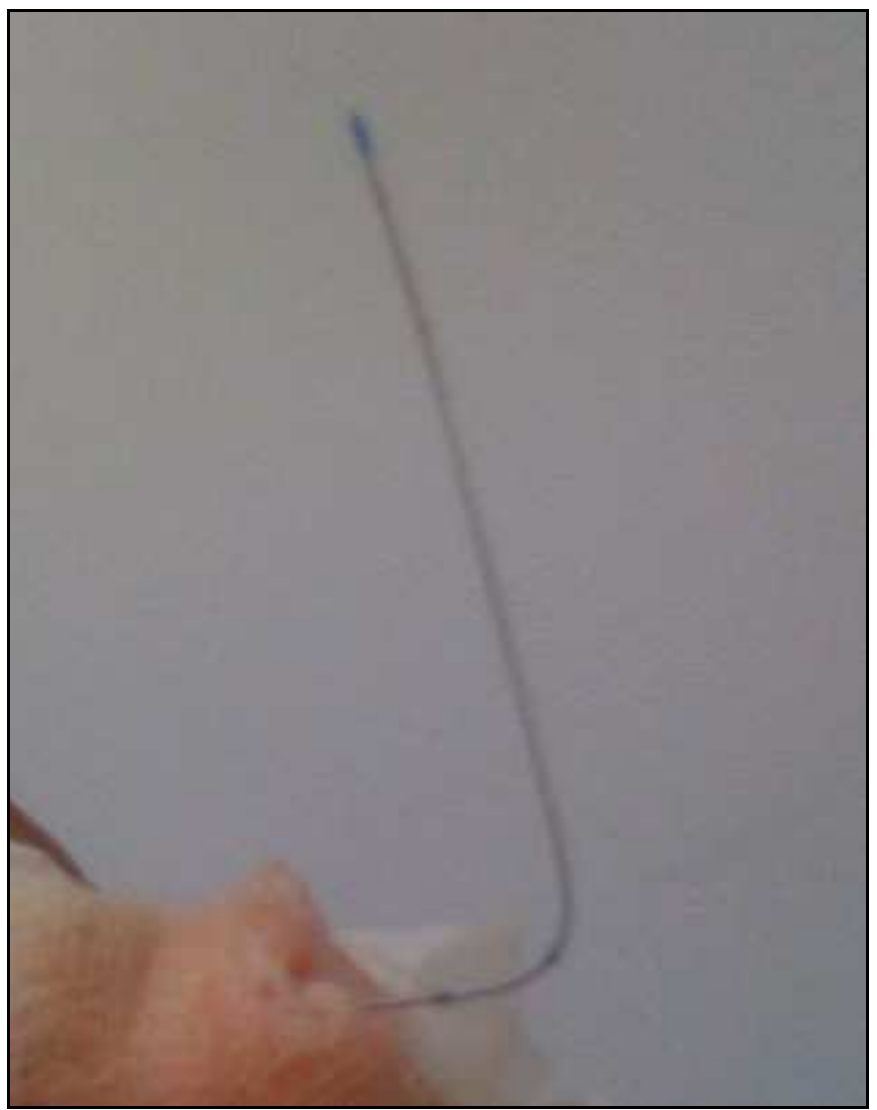

Photo 2. Median position of the catheter after extraction from the epidural space 


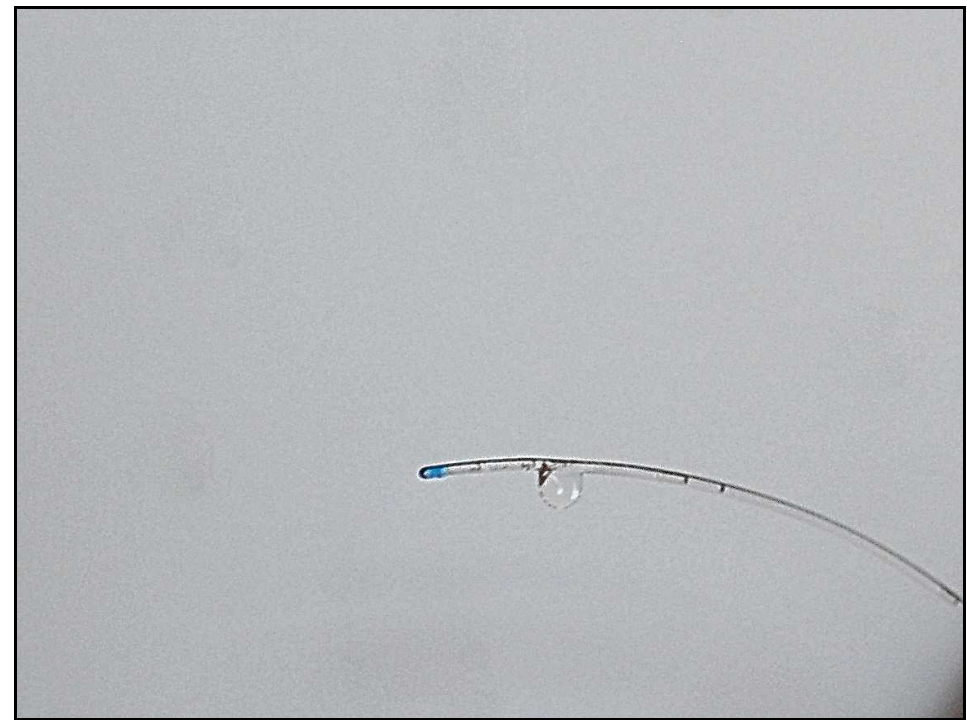

Photo 3. Illustrative image of the apparition of a single drop at the distal end of the catheter, following the administration of the analgesic substance in a continuous infusion

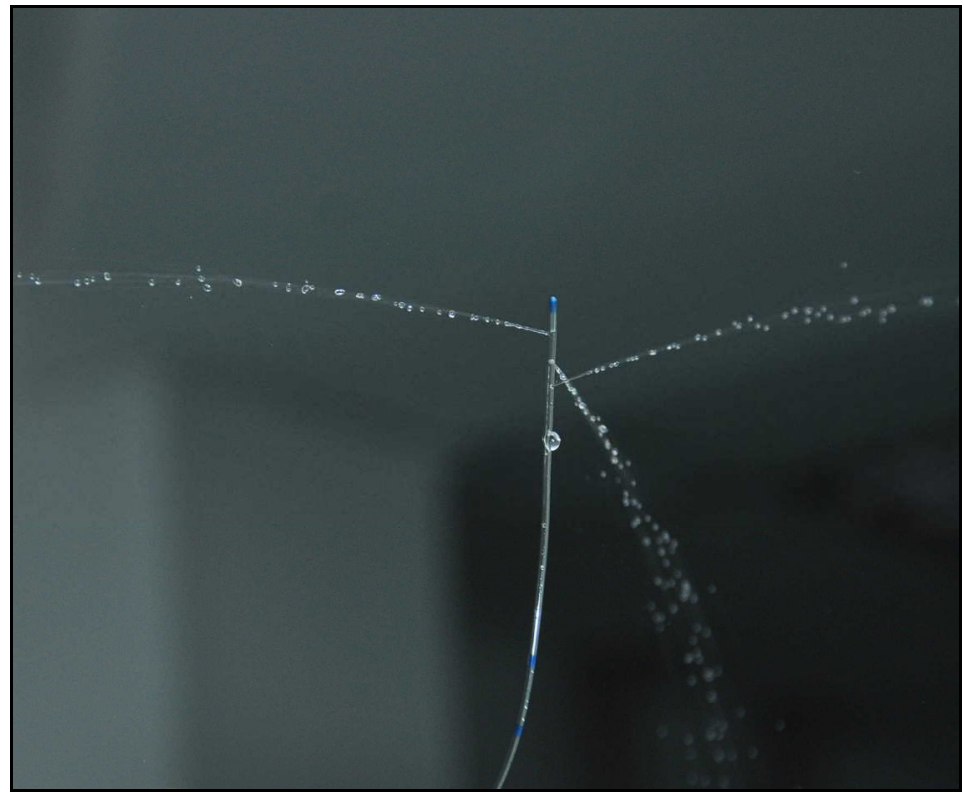

Photo 4. Administration of the analgesic substance in bolus 


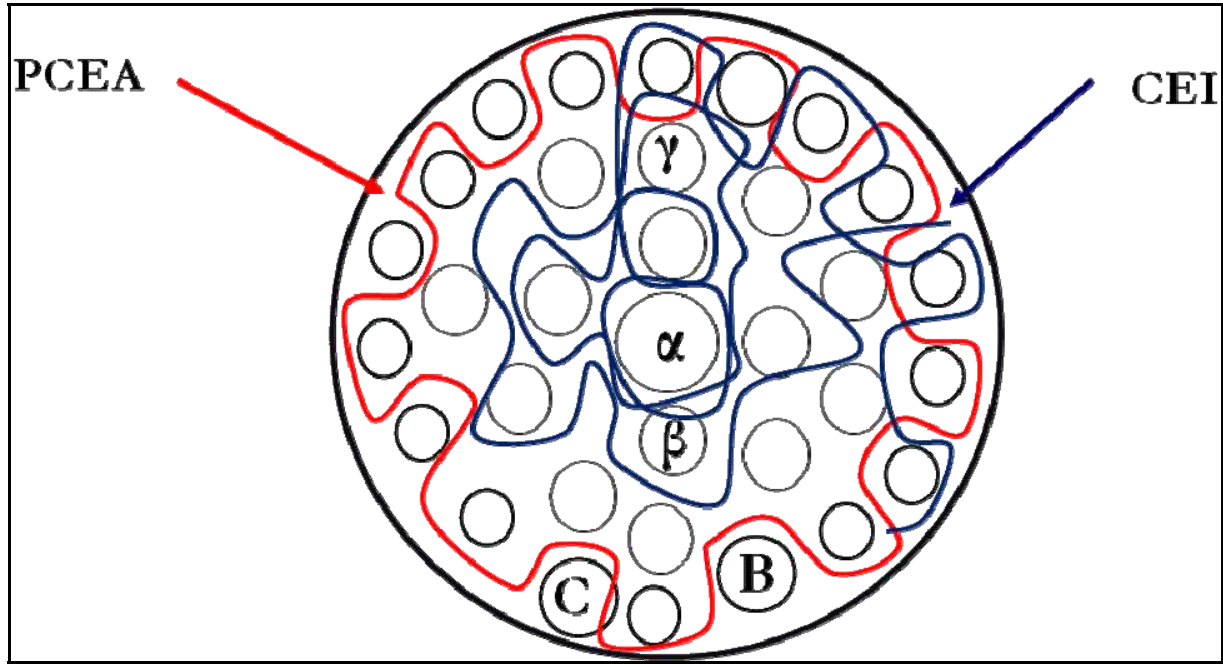

Represents the analgesic substance penetrating the periphery of the nerve fibre, using the PCEA method. method.

Represents the analgesic substance penetrating the periphery of the nerve fibre, using the CEI

Fig. 8. Schematic structure of the nerve fibre

Studies using MRI [Davidson EM et al., 2009], CT (See Figure 9), epiduroscopy, marked radioactive isotopes [De Biasi P et al., 2003] and studies on cadavers have demonstrated the existence of a vertical conjunctive septum and of horizontal septa which practically divide the epidural space [Aggarwal A et al., 2009]. These septa prevent the substance from diffusing amongst them, probably determining the asymmetry of the block. The small quantity of the substance infused using the CEI method may not succeed in distributing evenly throughout the epidural space. Even though the anterior epidural space is not well represented, in collaboration with our colleagues from the Chair of Imaging from the University of Medicine and Pharmacy in Cluj-Napoca, we have managed to emphasise the existence on this space, as well as of a median septum. (See Figure $10 \mathrm{a}, \mathrm{b}$ ). Frequent boluses in PCEA enable the substance to diffuse more easily amongst these septa, which upholds the theory stating that this technique is a major determinant in the apparition, intensity and symmetry of the block. There are studies in the speciality literature that mention the fact that the behaviour of the anaesthetic substance according to density also contributes to the apparition of the motor block [Aggarwal A et al., 2009].

Hence, the isobaric substance remains in the proximity of the place of injection, the hypobaric substance ascends from the place of injection, while the hyperbaric one descends. Moreover, the density of the anaesthetic substance varies inversely proportional to temperature. According to these principles, an isobaric substance at room temperature will become isobaric at bodily temperature, and if the patient is in left lateral decumbency, the most frequently encountered position in the current practice, the substance will ascend on the right side, determining an asymmetrical motor block. 


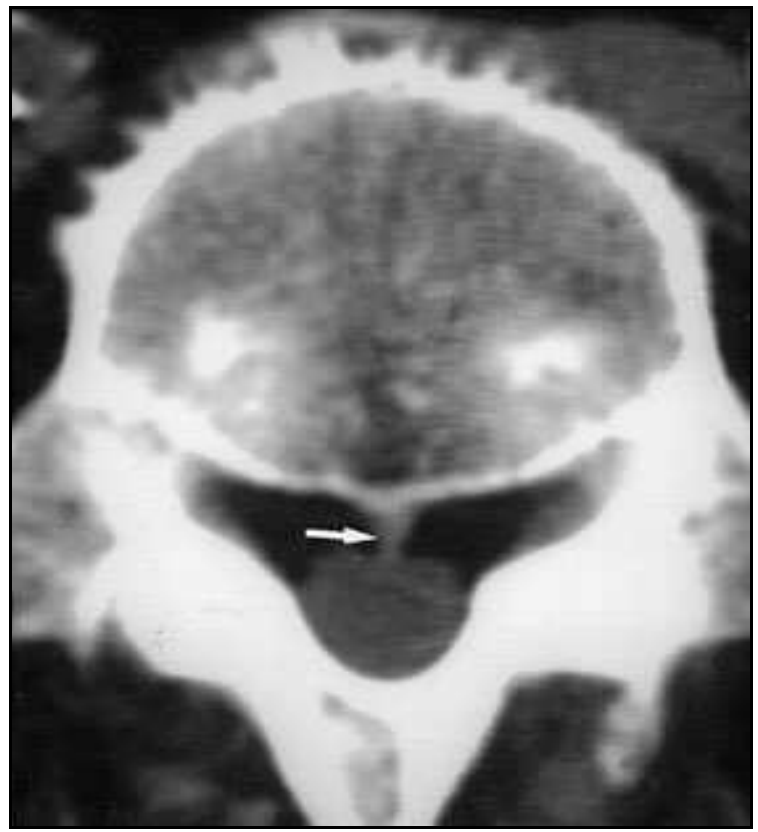

Fig. 9. CT axial section through vertebra S1. The median septum is clearly visible (arrow), dividing the epidural space into two separate compartments

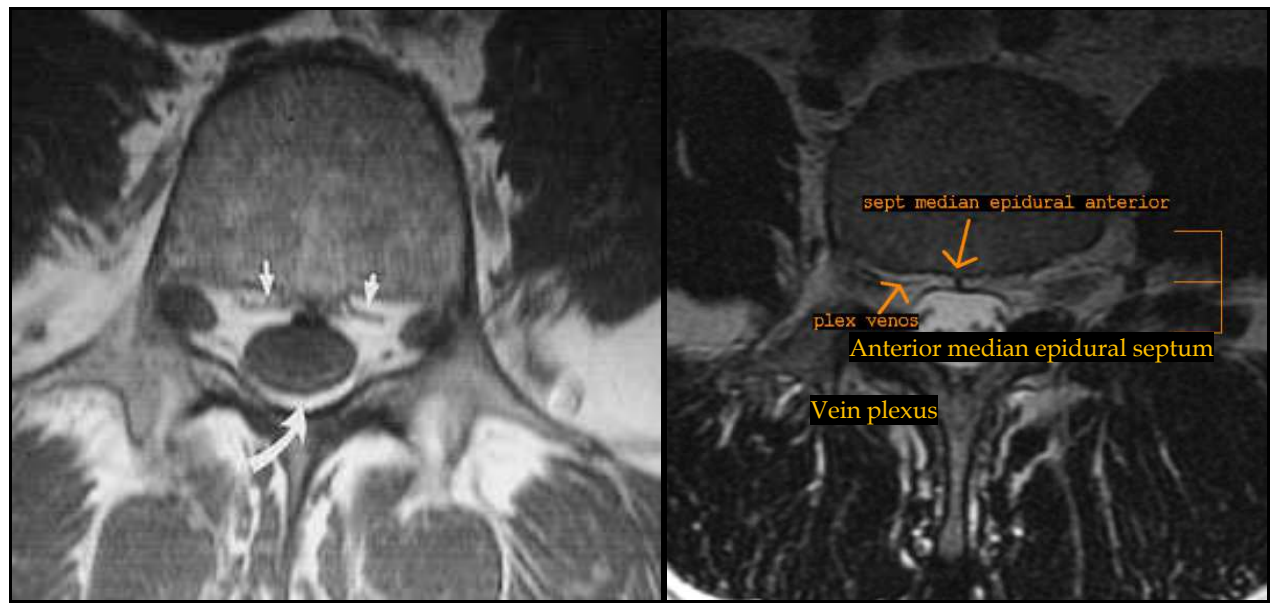

Fig. $10 \mathrm{a}$ and b. Axial MRI section T1 and T2 through a lombar vertebra at the pediculolamar level. The fat in the epidural space is clearly visible, in hypersignal, surrounding the dural sac. The anterior vein plexuses can be well individualised (arrows). The posterior epidural space is somewhat poorly represented (curved arrow Figure a). Figure b - anterior median epidural septum 
Our study has not emphasised any differences with regard to the time required for dilatation or the state of the foetus at the time of birth; however, the use of PCEA decreases the frequency and intensity of the engine block and reduces the need for an instrumental intervention, as the doses utilised are effective without there being a need to increase them.

The linearity of the VAS scale of quantifying pain varies between the two models, but the difference is statistically insignificant. (See Figure 11)

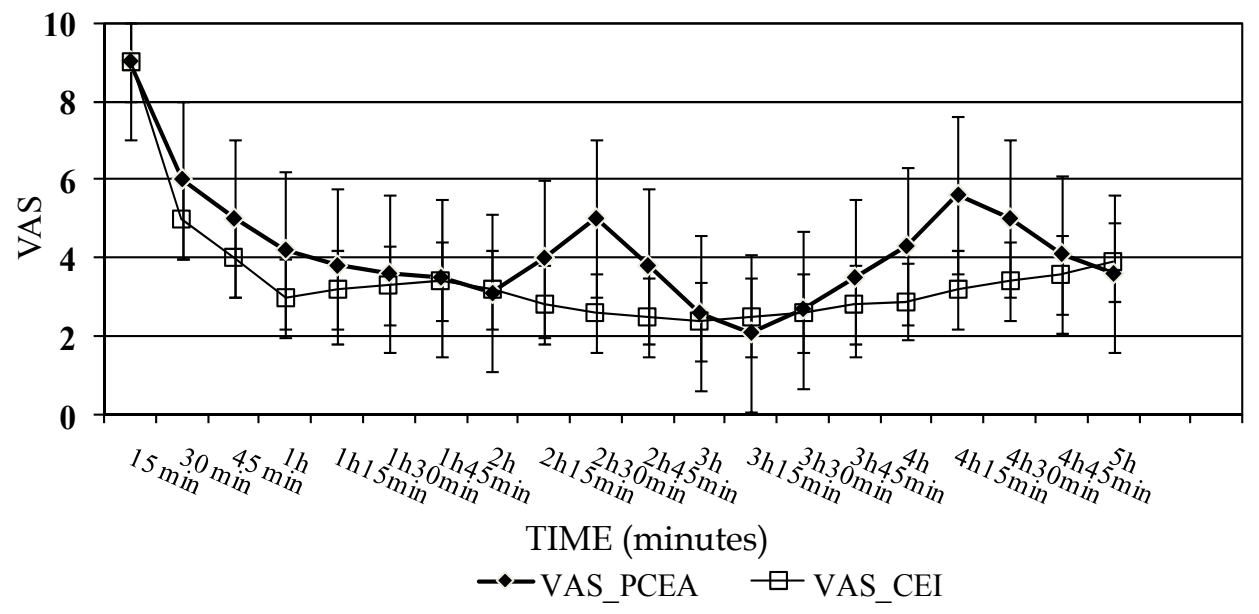

Fig. 11. VAS evolution in time, comparatively, in the two lots ( $\mathrm{p}=\mathrm{NS}$ )

CEI has ensured the decrease in frequency of the pain pick-ups on the VAS diagram during labour.

PCEA presents on the VAS diagram pick-ups corresponding to the increase in intensity of pain, which can be treated with the aid of the bolus doses placed at the disposal of the patient, without altering the high level of maternal satisfaction. The lack of a significant difference between the side effects of the two methods demonstrates the safety of the latter.

Although VAS linearity was maintained for CEI throughout labour, the analgesia at childbirth performed by means of the PCEA technique was appreciated by parturients, as they were their own deciders in controlling the pain.

In conclusion, although both techniques of epidural analgesia provide high maternal satisfaction, with a qualitatively good analgesia, PCEA offers the possibility to control pain while benefiting from the patient's collaboration. This simplifies the epidural analgesia protocol and decreases the number of invasive interventions from the part of the doctor. The technique ensures an individual calculation of the anaesthetic dose for an endurable degree of pain and decreases the number of instrumental interventions in the process of childbirth. Apart from these advantages, the absent or minimal motor block and the fall in the number of instrumental births using the PCEA technique are arguments worthy of taking into consideration in favour of this method. 


\section{PIEB}

For the first time in Romania, we have conducted a transversal study, descriptively, by using a relatively new technique at the global level, namely epidural analgesia at childbirth through programmed boluses (PIEB - Programmed Intermittent Epidural Bolus), by which one can avoid high fluctuations of the sensorial levels attained, as it has been noticed in the case of PCEA, and reduce the total consumption of anaesthetic, compared to CEI.

We have included in our study a number of 28 parturients, ASA I, with a gestation age of over 37 weeks, and applied the epidural catheter at a dilatation of the cervix of $3-5 \mathrm{~cm}$ and regular uterine contractions at every 2-3 minutes. We have again used levobupivacaine with no additives as a local anaesthetic. Forty five minutes after the initial bolus of $10 \mathrm{ml}$ of the $0,250 \%$ solution, we have administered regular boluses of $6 \mathrm{ml}$ from the $0,125 \%$ solution every 30 minutes until full dilatation.

Since in this study, the number of patients has been smaller $(n=28)$ compared to CEI $(n=53)$ and PCEA $(n=41)$, the lots not being homogenous, we have not made a comparison between these lots, though including all the obstetrical parameters in the same table (See Table 6).

\begin{tabular}{|l|c|c|c|}
\hline Parameters & PIEB (n=28) & PCEA (n=41)* & CEI (n=53) * \\
\hline $\begin{array}{l}\text { Cervix dilatation at initiation of } \\
\text { anesthesia (cm) }\end{array}$ & $3.2(3.1-3.3)$ & $3.1(3.1-3.2)$ & $3.4(3.1-3.7)$ \\
\hline Duration of labour (min) & $\begin{array}{c}130(120.5- \\
142.22)\end{array}$ & $\begin{array}{c}188.3(180.3- \\
196.4)\end{array}$ & $\begin{array}{c}168.5(162.2- \\
174.8)\end{array}$ \\
\hline Motor block (n, \%) & $3(10.71 \%)$ & $2(4.87 \%)$ & $21(39.7)$ \\
\hline Maternal satisfaction & High & High & High \\
\hline Childbirth by caesarean (n, \%) & $4(14.28 \%)$ & $4(9.75 \%)$ & $8(15.09 \%)$ \\
\hline $\begin{array}{l}\text { Instrumental childbirth } \\
\text { (vacuum extraction) (n, \%) }\end{array}$ & $1(3.57 \%)$ & $2(2.12 \%)$ & $14(14.89 \%)$ \\
\hline
\end{tabular}

Table 6. Obstetrical parameters in patients who benefitted from PIEB, PCEA and CEI

As noticed, there are major differences between the PIEB lot and the CEI lot, but the results are similar between the PCEA and PIEB lots. We have found no differences between the PCEA and PIEB lots regarding the effectiveness of the anaesthetic substance, maternal satisfaction or side effects. Four $(14,28 \%)$ parturients gave birth by caesarean due to malpresentation of foetuses (two of them had posterior rotation of the foetal occiput). In the case of a single pregnant woman it was necessary to have an instrumental childbirth. Posterior occipital rotation is frequent during labour, representing around $20 \%$ of all the positions at the beginning of labour and 5\% of those at birth [Hess PE et al., 2000; Gardberg $\mathrm{M}$ et al., 1998]. These malpositions of the foetus increase the rate of childbirths by caesarean and instrumental interventions, prolonging the second stage of birth and causing perineal ruptures. There are authors who consider that epidural analgesia would favour the posterior rotation of the foetal occiput. 
A study by Sebastiann et al. has shown that the regular use of programmed intermittent boluses could improve the function of the epidural catheter [American Society of Anesthesiologists Task Force on Obstetric Anesthesia, 2007]. Chua and Sia [Chua SM, Sia AT, 2004] have also noticed that PIEB represents a better alternative to childbirth analgesia than continuous perfusion.

We believe that analgesia at birth through programmed boluses is capable of ensuring rapid analgesia, extremely effective and with minimal motor block, low doses of local anaesthetic and increased maternal satisfaction (See Figure 12), thus it can rapidly become a widely utilised technique in alleviating pain [Dorca V et al., 2010].

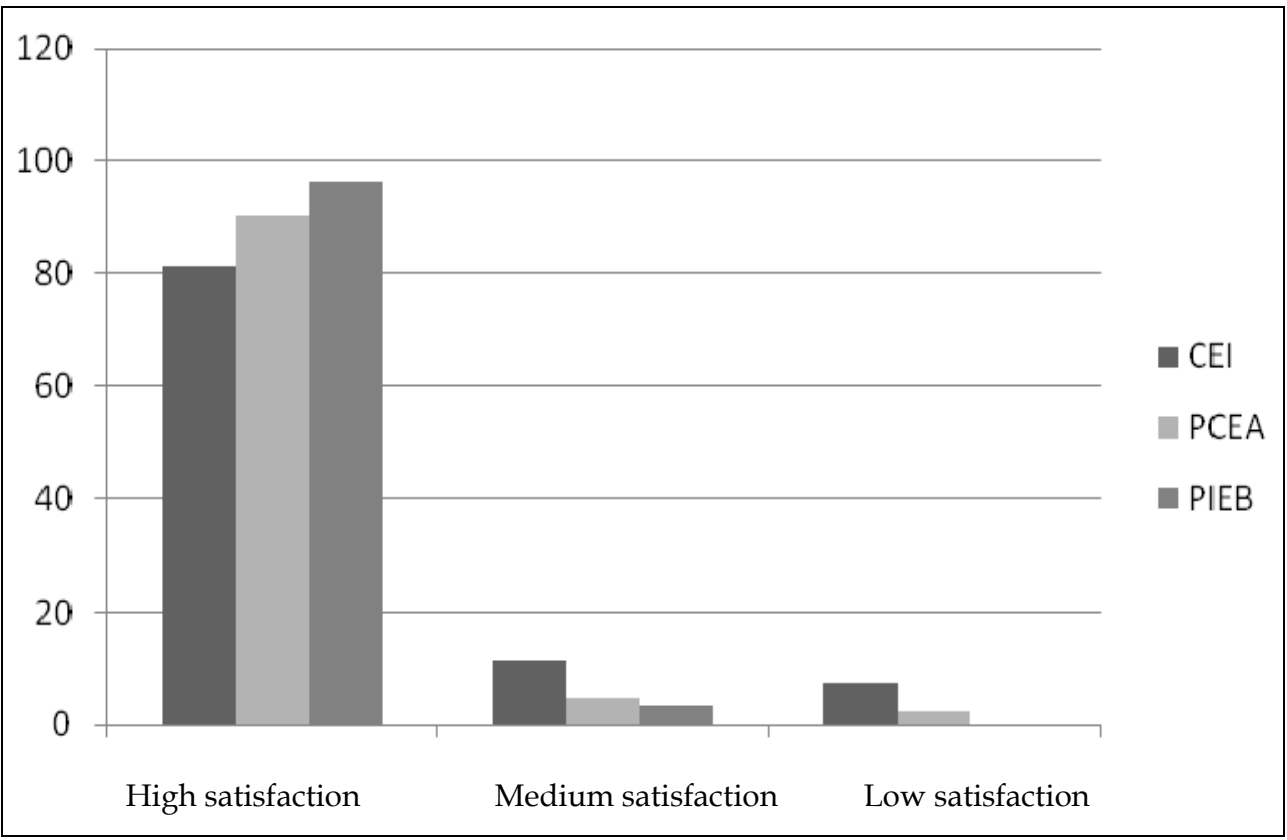

Fig. 12. Maternal satisfaction encountered in the three techniques utilised

In order to obtain rigorous results, it is necessary to conduct randomised studies which should validate this technique in the future. Since the infusion pumps that ensure a wellconducted analgesia through the PIEB technique are problematic [Sumikura $\mathrm{H}$ et al., 2004], it is our view that in the future, the technology incorporated into specialised electronic devices will solve this inconvenience.

\section{Conclusion}

The bolus injection of local anesthetic through an epidural catheter (PCEA/PIEB) has proven to be more efficient when considering the minimal intensity of motor blockade, the low local anesthetic consumption, the diminishing incidence of cesarean sections or instrumented deliveries and the parturient's satisfaction. However, in Romania, these techniques are not very popular yet. 
Contrary to the developed countries, continuous epidural analgesia in labor is not very popular in Romania as a consequence of the lack of information among parturients.

\section{References}

Abboud T, Schnider S, Wright R. Enflurane analgesia in obstetric. Anesth Analg 1980; 60:133137

Aggarwal A, Kaur H, Batra YK, Aggarwal AK, Rajeev S, Sahni D. Anatomic consideration of caudal epidural space: A cadaver study. Clin Anat. 2009 Jul 27

American Society of Anesthesiologists Task Force on Obstetric Anesthesia. Practice guidelines for obstetric anesthesia: an updated report by the American Society of Anesthesiologists Task Force on Obstetric Anesthesia. Anesthesiology 2007;106:843-63

Atherton MJ, Feeg VD, El-Adham AZ. Race, ethnicity and insurance as determinants of epidural use: analysis of a national sample survey. Nursing Economics. 2004;1:6-8.

Bonica J, Mc Donald JS. Principles and Practice of Obstetric Analgesia and Anesthesia. Williams \& Wilkins, Malvern PA, USA; 2nd edition 1995; 344-537

Bromage P R, Burfoot M F, Ceowell D E. Quality of epiduralblockade. I. Influence of physical factors. Br J Anaesth 1964; 36: 342-352

Bussche EV, Crombez G, Eccleston C, Sullivan M. Why women prefer epidural analgesia during childbirth: the role of beliefs about epidural analgesia and pain catastrophizing. European Journal of Pain. 2007;11:275-282

Cathelin MF: A new route of spinal injection: a method for epidural injection by way of the sacral canal: application to man. Compt Rend Soc Biol 1901, 53:452

Chua SM, Sia AT. Automated intermittent epidural boluses improve analgesia induced by intrathecal fentanyl during labour. Can J Anaesth. 2004;51(6):581-585

Davidson EM, Sklar E, Bhatia R et al. Magnetic Resonance Imaging Findings After Uneventful Continuous Infusion Neuraxial Analgesia: A Prospective Study to Determine Whether Epidural Infusion Produces Pathologic Magnetic Resonance Imaging Findings. Anesth Analg. 2009 Jun 11

De Biasi P, Lupescu R, Burgun G et al. Continuous lumbar plexus blocks: use of radiography to determine catheter tip location. Reg Anesth Pain Med 2003; 28:135-9

Dogliotti AM. A new method of block anesthesia: segmental peridural spinal anesthesia. Am J Surg 1934; 20:107

Dorca V, Feier D, Groza D, Mihu D, Chiorean M. Parturients' level of knowledge regarding labour analgesia in a university hospital- local exeprience. Cj Med. 2011; 84 (1): 93-97

Dorca V, Feier D, Balintescu A, Belciu I, Groza D, Ciuchina S. Analgezia peridurală cotrolată de către pacientă comparativ $c u$ infuzia peridurală continuă la naştere folosind levobupivacaina. J Rom Anest Terap Int 2009; 16:99-106

Dorca V, Feier Diana, D. Mihu, C. Todea. Programmed intermittent epidural bolus in labour: a cross-sectional study. Acta Med Marisiensis. 2010; 56 (4): 370-372

El-Hamamy E, Arulkumaran S. Poor progress of labour. Current Obstetrics and Gynecology. 2005;1:1-8

Ferrante F M, Rosinia F A, Gordon C, Datta S. The role of continuous background infusions in patient-controlled epidural analgesia for labor and delivery. Anesth Analg 1994; 79: 8084 
Ferrante F M, Lu L, Jamison S B, Datta S. Patient-controlled epidural analgesia: demand dosing. Anesth Analg 1991; 73: 547-552

Gadalla F, Lee SH, Choi KC, Fong J, Gomillion MC, Leighton BL. Injecting saline through the epidural needle decreases the iv epidural catheter placement rate during combined spinalepidural labour analgesia. Can J Anesth 2003; 50: 382-5

Gambling D R, Yu P, Cole C, McMorland G H, Palmer L. A comparative study of patient controlled epidural analgesia (PCEA) and continuous infusion epidural analgesia (CIEA) during labour. Can J Anaesth 1988; 35: 249-254

Gardberg M, Laakkonen E, Salevaara M. Intrapartum sonography and persistent occiput posterior position: a study of 408 deliveries. Obstet Gynecol 1998;91:746-9

Graffagnino P, Seyler LW. Epidural anesthesia in obstetrics. Am J Obstet Gynecol 1938; 35:597

Hess PE, Pratt SD, Soni AK, et al. An association between severe labour pain and cesarean delivery. Anesth Analg 2000;90:881-6

Lyons Gr, Kocarev MG, Wilson RC, Columb MO. A comparison of minimum local anesthetic volumes and doses of epidural bupivacanie $(0,125 \% \mathrm{w} / \mathrm{v}$ and $0,25 \% \mathrm{w} / \mathrm{v})$ for analgesia in labor. Anesth Analg 2007, 104: 412-5

Meister GC, D'Angelo R, Owen M, et al. A comparison of epidural analgesia with $0.125 \%$ ropivacaine with fentanyl versus $0.125 \%$ bupivacaine with fentanyl during labor. Anesth Analg 2000; 90:632-7

Minhas MR, Kamal R, Afshan G, Raheel H. Knowledge, attitude and practice of parturients regarding epidural analgesia for labour in university hospital in Karachi. The Journal of the Pakistan Medical Association. 2005;2:63-66.

Obst TE, Nauenberg E, Buck GM. Maternal health insurance coverage as a determinant of obstetrical anesthesia care. Journal of Health Care for the Poor and Underserved. 2001;12 (2):177-191

Owen MD, D'Angelo R, Gerancher JC, et al. $0.125 \%$ ropivacaine is similar to $0.125 \%$ bupivacaine for labor analgesia using patient-controlled epidural infusion. Anesth Analg 1998;86: 527-31

Paech M. Patient-controlled epidural analgesia. In: Birnbach D J,Gatt S P, Datta S, eds. Textbook of Obstetric Anesthesia. 1.Philadelphia: Churchill Livingstone; 2000: 189-202

Robert R, Gaiser RR. Labor epidurals and outcome (Best Practice and Research). Clinical Anaesthesiology. 2005;1:1

Rust G, Nichols M, Omole F, Minor P, Barasso G, Mayberry R. Racial and ethnic disparities in the provision of epidural analgesia to Georgia Medicaid beneficiaries during labor and delivery. American Journal of Obstetrics and Gynecology. 2004;2:456-462

Salim R, Nachum Z, Moscovici R, Lavee M, Shalev E. Continuous compared with intermittent epidural infusion on progress of labor and patient satisfaction. Obstetrics and Gynaecology. 2005;2:301-306

Schlotterbeck H, Schaeffer R., Dow W.A. et al.: Ultrasonographic control of the puncture level for lumbar neuraxial block in obstetric anesthesia. Br J Anaesth 2008; 100:230-4

Sumikura H, van de Velde M, Tateda T. Comparison between a disposable and an electronic PCA device for labour epidural analgesia. J Anesth 2004;18:262-6

Van der Vyver M, Halpern S, Joseph G. Patient-controlled epidural analgesia versus continuous infusion for labour analgesia: a metaanalysis. Br J Anaesth 2002; 89: 459-465. 


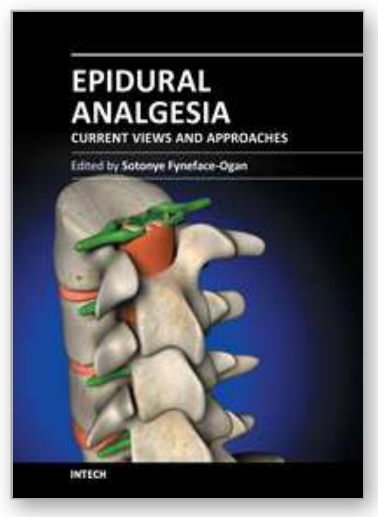

\author{
Epidural Analgesia - Current Views and Approaches \\ Edited by Dr. Sotonye Fyneface-Ogan
}

ISBN 978-953-51-0332-5

Hard cover, 174 pages

Publisher InTech

Published online 16, March, 2012

Published in print edition March, 2012

Epidural analgesia is a form of pain relief administered through the space surrounding the dural sheath either by direct injection or via catheter. The agent, when administered, can cause both a loss of sensation (anesthesia) and a loss of pain (analgesia), by reversibly interrupting the transmission of signals through nerves in or near the spinal cord. This form of pain relief has been found useful in many clinical situations. This book intends to provide an in-depth review of the current knowledge on epidural analgesia. The use of this form of analgesia is explored by contributors from different perspectives, including labor and delivery, postoperative analgesia in both pediatric and geriatric patients, and its role during anesthesia and surgery. In order to provide a balanced medical view this book was edited by an obstetric anesthesiologist.

\title{
How to reference
}

In order to correctly reference this scholarly work, feel free to copy and paste the following:

Virgil Dorca, Dan Mihu, Diana Feier, Adela Golea and Simona Manole (2012). Actualities and Perspectives in Continuous Epidural Analgesia During Childbirth in Romania, Epidural Analgesia - Current Views and Approaches, Dr. Sotonye Fyneface-Ogan (Ed.), ISBN: 978-953-51-0332-5, InTech, Available from: http://www.intechopen.com/books/epidural-analgesia-current-views-and-approaches/actualities-andperspectives-in-continuous-epidural-analgesia-during-childbirth-in-romania

\section{INTECH}

open science | open minds

\author{
InTech Europe \\ University Campus STeP Ri \\ Slavka Krautzeka 83/A \\ 51000 Rijeka, Croatia \\ Phone: +385 (51) 770447 \\ Fax: +385 (51) 686166 \\ www.intechopen.com
}

\author{
InTech China \\ Unit 405, Office Block, Hotel Equatorial Shanghai \\ No.65, Yan An Road (West), Shanghai, 200040, China \\ 中国上海市延安西路65号上海国际贵都大饭店办公楼 405 单元 \\ Phone: +86-21-62489820 \\ Fax: +86-21-62489821
}


(C) 2012 The Author(s). Licensee IntechOpen. This is an open access article distributed under the terms of the Creative Commons Attribution 3.0 License, which permits unrestricted use, distribution, and reproduction in any medium, provided the original work is properly cited. 